\title{
Discussion of impact of relics activation on protection and utilization approaches-take The Old Summer Palace as an example
}

\author{
Jiao Xiaoqi \\ Jiao Xiaoqi,Tsinghua Heritage Institute For Digitization, Shangdi West Street, Beijing,-jiaoxiaoqi@thid.cn
}

KEY WORDS: relics ; activation of relics; protection of relics; the Old Summer Palace ; culture; tourism

\begin{abstract}
:
As the popularization of cultural relics and the rapid development of cultural tourism industry, a large number of cultural relic tourism resources goes into public eyes. Activation of relics has became an important way for tourist to contact and understand culture relics. The way of how to properly interpret the historical sense and cultural uniqueness to the masses of tourists in order to achieve social service functions of relic resources has always been research focal point of site protection and utilization, so nowadays it has important significance to protection and utilization of heritage resources in our country. From the point of activation of relics and based on the analysis of resource characteristic, the paper in depth discuss ways of activation of relics of the Old Summer Palace, in order to provide reference for sustainable development of sites tourism in China.
\end{abstract}

\section{Introduction}

As the popularization of cultural relics and the rapid development of cultural tourism industry, a large number of cultural relic tourism resources goes into public eyes. Activation of relics has became an important way for tourist to contact and understand culture relics. The way of how to properly interpret the historical sense and cultural uniqueness to the masses of tourists in order to achieve social service functions of relic resources has always been focal point of site protection and utilization research. Recent years it has even been widely concerned by government and scholars. In 2013, President Xi Jinping put forward 'let the collected cultural relics in the museum, exposed heritage in the vast earth and written words in ancient books alive', the theme of cultural heritage day is "Let the cultural heritage alive" .

The concept of relic activation originates from Taiwan, and continuous improved in the process of heritage protection and utilization, its focused emphasis is how to let heritage known to the public, enhance public awareness of the heritage value and promote heritage conservation in order to achieve sustainable development of heritage tourism. ${ }^{[1]}$

Nowadays is the new phase of national archaeological park acted as great site protection. Protection and utilization of heritage mainly emphasize on cultural heritage resources integration, protecting exhibition of ideal innovation and its bringing impact of economic improvement and social participation. Then activation of relics provides important work ideas for current site protection and utilization. As the first important big relics in China, the protection and utilization of Old Summer Palace has mostly been concerned, and it has good study basis and practical condition for relic activation.

\section{Activation of relics}

\subsection{Activation of relics}

The concept of relic activation originated from the background of industrial heritage protection and utilization. Then the concept of relics the concept was widely been used in the practice and research area of relic protection and utilization. As its name suggests, the concept of relic activation is converting cultural sites from the state of cultural relics to the state of suitable for touring which based on relic protection, in order to let more and more people known the history and culture hidden in the historic site which was understand by few people. Actually the process of relic activation is the process of rational use of historic site.

\subsection{Principals of relic activation}

\subsubsection{Authentic principal}

Authenticity is the key principle of cultural relic protection and utilization, and also main charm to attract customers as a historical sites ${ }^{[2]}$. It's divided into historical authenticity, scenic authenticity and constructional authenticity.

Historical authenticity stressed ruins exist to show and so absolutely original, with no artificial ingredients; Authenticity style emphasizes the external environment and landscape ruins ruins surrounding natural and cultural match, allow respect for historical facts on the basis of cultural or natural sites which environment appropriate amendments to ensure a more comprehensive display of historical information contained in the original site; Authenticity constructed primarily for public display should not be done on the relics of the reproduction process, namely the performance by copying the site, allowing the site appropriately the re-creation process.

The cultural cites which contents historical information always goes through a long period of time and are damaged by natural factors, its cultural and archaeological value is usually not easy to understand for the general public. Therefore the process of activation need to re-creation and management, in order to 'interpret' the information. The "interpretation" process must adhere to the authenticity principle, so that the tourists could be convinced.

Table 1: The meaning of authenticity and request of activation

\begin{tabular}{|l|l|l|}
\hline Authenticity & Meaning & $\begin{array}{l}\text { request of } \\
\text { activation }\end{array}$ \\
\hline
\end{tabular}




\begin{tabular}{|c|c|c|}
\hline $\begin{array}{c}\text { Historic } \\
\text { authenticity }\end{array}$ & $\begin{array}{l}\text { The authenticity of } \\
\text { objective angle of } \\
\text { historical events, site } \\
\text { ground bureau, } \\
\text { function and Cultural } \\
\text { relic, emphasize on the } \\
\text { 'real'existence of } \\
\text { historical culture. }\end{array}$ & $\begin{array}{l}\text { Strict protection of } \\
\text { the ruins, relics etc. }\end{array}$ \\
\hline $\begin{array}{c}\text { Scenic } \\
\text { authenticity }\end{array}$ & $\begin{array}{c}\text { The overall } \\
\text { coordination between } \\
\text { natural \& cultural } \\
\text { environment of heritage } \\
\text { sites and Architectural } \\
\text { style \& community } \\
\text { layout, emphasize on } \\
\text { the overall protection } \\
\text { and utilization of } \\
\text { history and culture. }\end{array}$ & $\begin{array}{c}\text { Take full } \\
\text { consideration about } \\
\text { relationship } \\
\text { between relics and } \\
\text { surroundings, such } \\
\text { as relationship } \\
\text { between site layout } \\
\text { and massif, river } \\
\text { etc. }\end{array}$ \\
\hline $\begin{array}{l}\text { Constructiona } \\
1 \text { authenticity }\end{array}$ & $\begin{array}{l}\text { With the help of the } \\
\text { technology and the } \\
\text { artistic performance, } \\
\text { build sites intangible } \\
\text { cultural heritage into } \\
\text { the state of some period } \\
\text { of history }\end{array}$ & $\begin{array}{l}\text { Based on the } \\
\text { authenticity of } \\
\text { history, along with } \\
\text { certain scientific } \\
\text { and rational re- } \\
\text { creation process }\end{array}$ \\
\hline
\end{tabular}

\subsubsection{The protective principle}

Activation process should follow the principle of "protection first, develop second", and achieve the goal of protection and tourism through ongoing management.

Protected sites by saving, recovery and transformation of the way. Preservation of existing sites that maintain state, because the existing state itself has some heritage significance, such as Western-style western part of the Yuanmingyuan. Ruins of the recovery requires completely ruins scattered partially restored its original state at a certain historical period, but the actual operation to allow the use of new materials mark. Generally refers to the transformation of the site does not change the building's original appearance, structure, and function of its internal or appropriate changes, this approach is more common, such as the National Palace Museum treasures. In practice, according to the site of activation may retain the status quo, protection requirements to determine which way to protect it.

Pay attention to body site protection and research work is the basis of the site activation, especially for nonrenewable historical relics, once they were damaged, it is difficult for people to recover. This will not only affect the development of tourism economic benefits, but also unable to restore the cultural loss. In order to let the public can understand the important historical events and its value, moreover to realize the sustainable utilization of site resources, it is necessary to protect them strictly.

\section{Current situation of the Old Summer Palace}

\subsection{Lack of surface residue and esthetics}

The relic of the Old Summer Palace is buried underground, and there is few residue retained on the ground. Statistics show that the total building area of three parks in the Old Summer Palace in the heyday was $160000 \mathrm{~m}^{2}$, but the total building area of residue is $3950 \mathrm{~m}^{2}(2.47 \%)$. The residue mainly consists of low stylobates, which has poor scenery and has been one of obstacles for activation work.

Such as Jianyuan site, locates in the southeast of changchun park scenic area, east is close to the walls, wading in the western conference. There is no archaeological work carried out as a park site, nor any protective measures, sites in outdoor conditions, most of the soaking in the water. Sites are scattered in construction, the surrounding overgrown and poor overall site condition.



Figure 1. the Old Summer Palace site which is lack of esthetics

3.2 Interpretation system needs to be perfected and tourists "interpretation" is difficult

The status of the Old Summer Palace most consists of underground ruins which ground ruins are incomplete. The auxiliary facilities such as interpretative signs are only simple text description and pictures. This is difficult for tourists to interpret the ruins. Thus historical information contained in the site will not be able to accurately convey.

The Jie xiu shan fang area, the site is in the open state of conservation, most of the building components stacked disorganized, difficult to understand site visitors from the status quo, the only one of the explanatory signs are more simple, just describe the access time and the surrounding housing construction Jie xiu shan fang environment, not including construction background, function and other aspects, can not effectively explain to visitors take Jie xiu shan fang resort brought some culture.

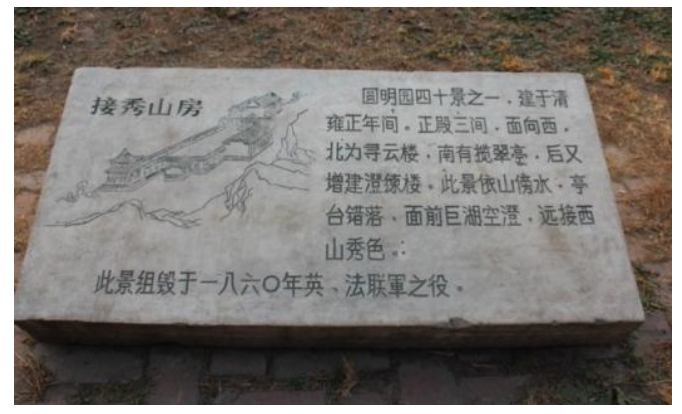

Figure 2. Boring commentary facilities

\subsection{Disorder construction has brought greater pressure to overall style is preservation}

Old Summer Palace status within buildings, roads, Bridges and all kinds of service facilities due to lack of unified planning and construction, not only tie up site phenomenon found in large Numbers, all kinds of different styles of buildings, Bridges and 
roads is also directly affect the overall style and features of the zoo, destroyed the old Summer Palace style of the original true. Most of the park without a design that is building bridges and culverts, the presence of bright colors, scale inappropriate material too modern and bridge superior site location is not a problem. Yuanmingyuan bridge is not only a means of transport within the park's landscape is also to convey the historical information, should be treated with caution.

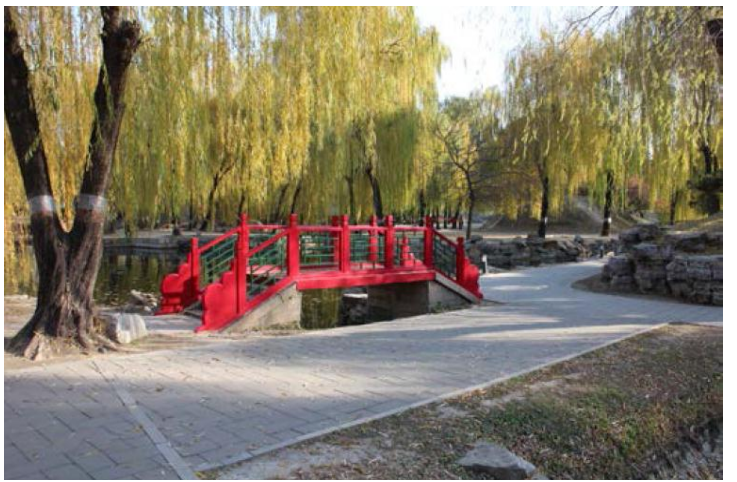

Figure 3. Architectures and structures which affect palace landscape

\section{Pathway analysis of activation of the Old Summer} Palace

\subsection{Content of activation}

\subsubsection{Body activation of relics}

Body activation of relics means to improve visibility and performance of the ruins. Ruins, relics can bring the feeling of familiarity and comfort, or a sense of belonging ${ }^{[3]}$. The basis which causes this feelings of sympathy, Is to let the tourists can see the ruins in the history of the state, and to remember and think about history through understanding. According to the site to maintain the status quo, the presence of state can adopt different activation pathways. Well or basic well preserved ruins carriers, such as the only well-preserved wood-structure architecture-Zhengjue Temple can be displayed originally after a little bit fixing. While ruin carriers which are badly damaged or even unable to see, the activation of the difficulty will greatly increase. Most of relics in the palace are seriously damaged, repair is obviously not a good way for activation, such as ruins of Jiuzhouqingyan. For this type of site, we can mainly focus on authenticity of historical information involved in relics, instead of constrained by the site material carrier ${ }^{[4]}$. Through related technology to interpret and reproduce historical and cultural value in ruins can realize the information convey.

\subsubsection{Activity activation}

Tourists are main body in tourism activities, therefore how to satisfy tourists' physical and mental need and enhance abundance of touring experience, which is also important content of the relic activation. Relic touring should not be cramming exhibition, and also not give visitors a sense of awe superior, it should try to let visitors experience the feeling. If we integrate entertainment experience elements into ruins touring, after the visitors' experience, they will even treasure these sites and consciously establish relics protection consciousness. Tourist activities need to highlight the activation of a warm and friendly service, embodies the people-oriented principle.

\subsection{Activation pathways}

\subsubsection{Body activation pathways}

\section{(1) Rehabilitation}

Rehabilitation mode refers to the recovery of the construction site, a visual representation of the site to visitors by entities presenting ways. Considering the ruins of their own values, conservation status and other factors to determine the construction program, such as site rehabilitation, across empty rehabilitation, reconstruction and other places.

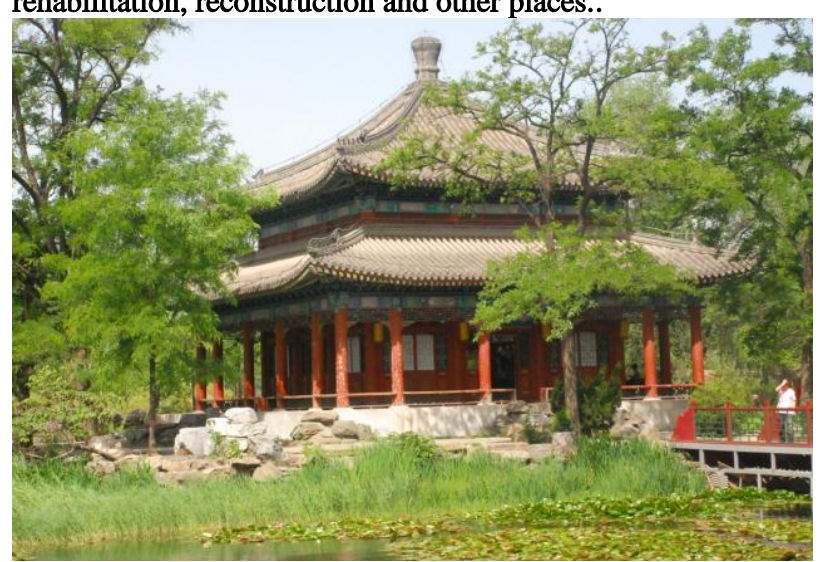

Figure 4. rehabilitation of "Jian bi" Pavilion

This approach applies to have a significant impact on the history of the spatial pattern of historic construction sites, historical value and outstanding landscape value, to better reflect the historical pattern of the original Yuanmingyuan and landscape architecture. Advantage of this approach is to visually show the ruins of the original style, good structure reflects the historical pattern and landscape sites. Yuanmingyuan Ruins area as palace gate of Yuanmingyuan, was the big main entrance area of the Old Summer Palace. Therefore, the large palace occupies a pivotal position in the Yuanmingyuan Ruins, the need to restore the Old Summer Palace complex built by the overall pattern of the way。 Meanwhile, the reconstruction of the site has some way to disturbance and destruction, so before rehabilitation, basic research work on the site to be a solid and adequate; archaeological sites have been excavated, the site is accurate, do their utmost to improve rehabilitation credibility。

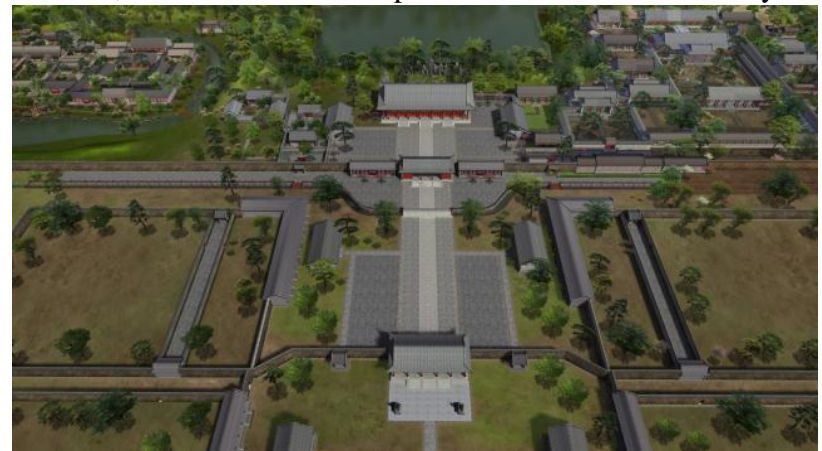

Figure 5. Restoration plan of Yuanmingyuan palace gate 
Table 2 The old Summer Palace rehabilitation of buildings

\begin{tabular}{|c|c|c|c|c|}
\hline $\begin{array}{l}\text { Belonging to } \\
\text { the park }\end{array}$ & $\begin{array}{l}\text { Name of } \\
\text { buildings }\end{array}$ & Function & $\begin{array}{l}\text { Area } \\
\left(\mathrm{m}^{2}\right)\end{array}$ & $\begin{array}{l}\text { Time for } \\
\text { completion }\end{array}$ \\
\hline \multirow{4}{*}{$\begin{array}{l}\text { Qi chun } \\
\text { yuan }\end{array}$} & Palace Gate & $\begin{array}{l}\text { Transport, } \\
\text { exhibition }\end{array}$ & 369.2 & 1986 \\
\hline & $\begin{array}{l}\text { Hao ran } \\
\text { Pavilion }\end{array}$ & $\begin{array}{c}\text { rest } \\
\text { exhibition }\end{array}$ & 25 & 1992 \\
\hline & $\begin{array}{c}\text { Jian bi } \\
\text { Pavilion }\end{array}$ & $\begin{array}{c}\text { rest } \\
\text { exhibition }\end{array}$ & 256 & 1992 \\
\hline & Zheng jue si & exhibition & 3649 & 2011 \\
\hline \multirow{2}{*}{$\begin{array}{c}\text { Chang chun } \\
\text { yuan }\end{array}$} & $\begin{array}{c}\text { Palace Gate } \\
\text { and room }\end{array}$ & $\begin{array}{c}\text { Transport,e } \\
\text { xhibition }\end{array}$ & 534.4 & 2009 \\
\hline & $\begin{array}{l}\text { Huang hua } \\
\text { zhen }\end{array}$ & $\begin{array}{c}\text { rest, } \\
\text { exhibition }\end{array}$ & 43 & 1986 \\
\hline \multirow{3}{*}{$\begin{array}{l}\text { Yuan ming } \\
\text { yuan }\end{array}$} & $\begin{array}{c}\text { Peng dao } \\
\text { yao tai west } \\
\text { yard }\end{array}$ & $\begin{array}{c}\text { rest } \\
\text { exhibition }\end{array}$ & 123.1 & 1986 \\
\hline & $\begin{array}{l}\text { Ying hai } \\
\text { xian shan } \\
\text { Pavilion }\end{array}$ & $\begin{array}{c}\text { rest } \\
\text { exhibition }\end{array}$ & 27.4 & 1986 \\
\hline & $\begin{array}{l}\text { Bie you } \\
\text { dong tian } \\
\text { Pavilion }\end{array}$ & $\begin{array}{c}\text { rest } \\
\text { exhibition }\end{array}$ & 37.45 & 1986 \\
\hline Summation & - & - & 5065 & - \\
\hline
\end{tabular}

\section{(2) Virtualization}

Virtualization is a conceptual exhibition model that use sign exhibition and digital exhibition as main means to display the site .Sign exhibition displays the site characteristi such as overall pattern,building contour by disigned vegetation,paving etc.Digital exhibition makes the site the history visual by the application of computer virtual technology.Based on the Internet, cloud computing, Internet of things, the augmented reality experience technology, taking the massive historical information data as the core, design two axes in the principle of "refinement" and"intelligence" ,making the the site, exhibition,computing,service an organic whole, by means of scientific protection and digital exhibition,using diversified forms of cultural display to make the site landscape intuitively reappear in mobile navigation,audio introduction,multimedia,interactive application.Virtualization can make tourists feel history just like being personally on that scene ,and ideally solving the fundemental question that site culture is difficult to be learned,to be understood,to be transmitted.

beacuse of its large scale and massive sites Old Summer Palace is very hard to be rebulided.Meanwhile rebuilding may disturb the site protecting even do damage to the site.Tourist can get overall knowledge of the building contour and layout through sign exhibition.Such as ruins of Han jing tang, the use of brick ruins of the original package, in order to show the building's original base address. Gray tiles assembled, during which representatives of brick red "lian di kang" and column bases.

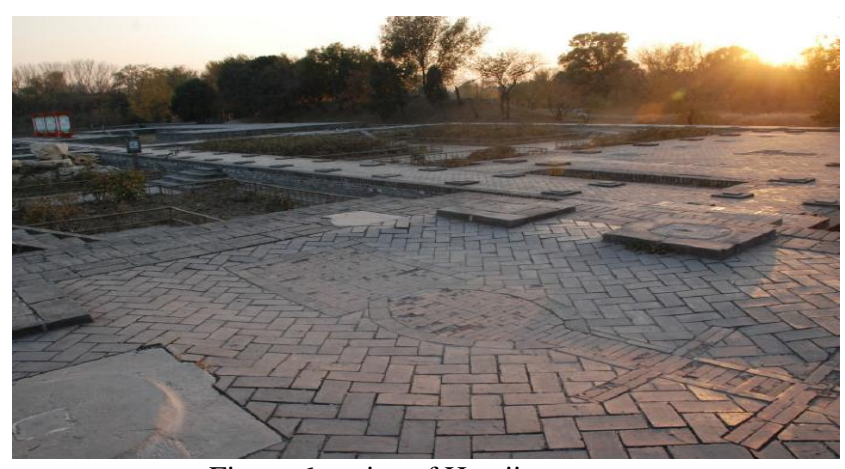

Figure 6. ruins of Han jing tang,

At the same time, with the development of the intelligence industry, we can reconstruct the landscape of garden of gardens through digital technology, all the tourist also can get their insignt to royal gardens and buildings of Qing dynasty and comprehend the subtlety of Yuanming by using mobile terminals,such as ceilphones,IPAD,etc.

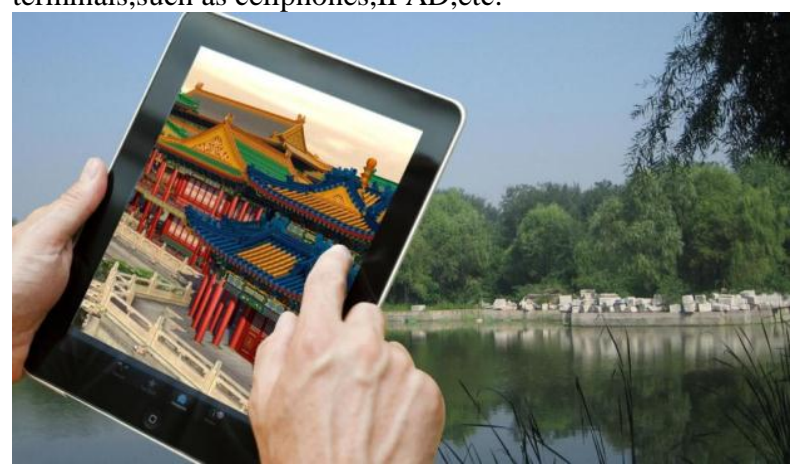

Figure 7. digital exhibition with Ipad

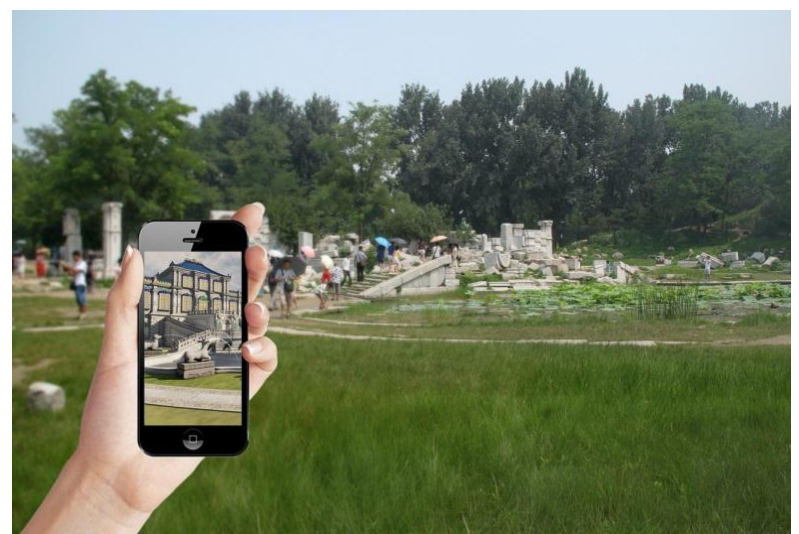

Figure 8. digital exhibition with ceilphone

\subsubsection{Activities activation ways}

Dynamically display the static resources is the core of tourist activities activation. While dynamic display give to tourists Spiritual pleasure is need by fully explore the relic in variety of senses, visual, auditory, tactile.

(1)reproduce historical scenes to enhance visual experience of tourists

Scene reproduction is a widely used way in the current relic activation, including reproduction and distribution space static, dynamic historical events, etc which includes not only the historical events in ruins land, etc., can also be reproduced site protection processes. The biggest advantage is that this 
approach greatly improves the ruins of ornamental and interesting, make dull historical records and research become vivid images. As xi 'an Da ming palace, in okimichi square arrangement subject-live performance - “dan feng ying bin”, through creative artistry, a repeat of the highest level of tang period the royal welcome ceremony。

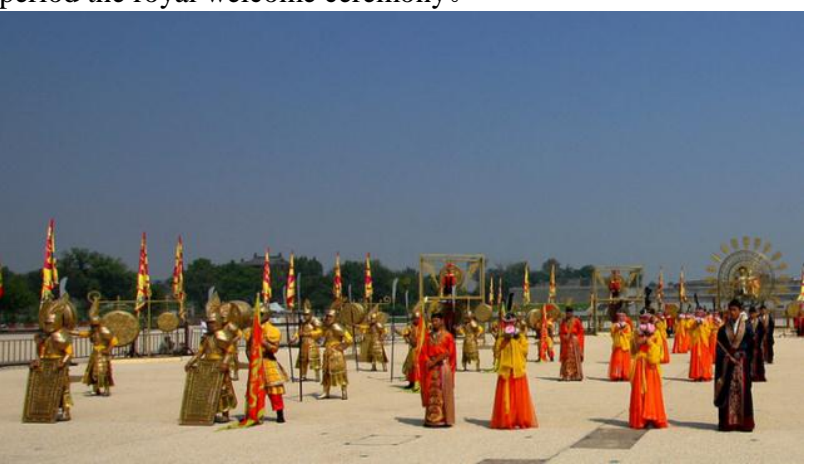

Figure 8. live performance - "dan feng ying bin"

In the qing dynasty royal lifestyle is an important cultural heritage o fthe Old Summer Palace, like watching the play in Tong Le Yuan,watching the horse racing in Shan Gao Shui Chang ,etc,Therefore a carefully planned large-scale performing arts or ceremony, etc can be used to reproduce the historical scenes. Held in Shan Gao Shui Chang such as the eight banners riding and shooting performance, activities such as riding stunts, simulated battle scenes. Using the simulation range environment at the same time, encourage visitors to participate in the experience. Archaeological work or can be combined with the on-site condition, archaeological work site open to the tourists, introduces the archaeological basic working methods, modern tools. At the same time also can create a simulated archaeological sites, let visitors to participate in the archaeological work, understanding of the cultural relics excavated, the research process. Is important to emphasize that "historical representation" is the most important principles of respect for history, emphasis on building the original true.

\section{(2) the optimization of explanation function, arouse tourists}

\section{auditory perception}

Tourists to the site of touring experience acquired mainly depends on the understanding of history, and this is mainly by means of explanation. Studies have shown that tourism interpretation has an important influence on tourism experience and emotion ${ }^{[5]}$.The divide in space and time to make a person feel sense of distance and rusty, hence to appreciate and understand historical remains is difficult. Wonderful explanation can help visitors easy to understand these specialized information, the more likely to prompt it to "understand and appreciate, and by appreciation and love, because love and protect" ${ }^{\text {"[6] }}$.As people's understanding of things is to adapt the particular situation of known models, so choose the appropriate explanation way could also affect site activation effect is bigger.

Old Summer Palace existing interpretation system is not perfect. The current interpretation system is make western house as a core to organize, lock the old Summer Palace in the category of national humiliation testimony and no description of royal garden features. Such as Zhengjue temple as the old Summer Palace only preserve the historical buildings, not be reflected in the commentary route. Ironically, the Yuan Ming Garden as the largest palace in Yuan Ming Three Gardens evens no explanation system at the moment. So to realize the Old
Summer Palace ruins activation on interpretation system must in order to overall planning and promotion. First, you need to comb cultural system combined with the present situation of the scenic spots in Ming, looking for unique narration theme for various attractions, such as Dagongmen and Zheng Da Guang Ming scenic highlight the cultural explanation to the royal government affairs; Second, pay attention to use a variety of explanations, including placards, subject, since the tour guide to diameter, exhibitions, audio-visual media, self-help type voice guide, narrator, etc., comprehensive, systematic, in-depth and vividly show round bright culture; Finally, with the scene explanation, more intuitive to show the historical and cultural value of the old Summer Palace, such as by the Qing dynasty costumes interpreter ought to show historical scene or event, this can activate the "history" of cultural expression, to provide tourists with more intuitive viewing experience ${ }^{[7]}$.

(3) with the aid of festival activities, create the comprehensive experience atmosphere of Old Summer

\section{Palace culture}

Festival celebrations which are rich in local characteristics usually able to display local cultural and with high ornamental and good experience, can greatly increase the attraction of local culture. The festival celebration activities that can not only display the charm of history and culture, but also with highly ornamental and participatory., and highly make the ruins into visual\&artistic ones, which brings a strong integrated experience to tourists, such as opening ceremony of the ancient city of Pingyao, tea culture activities of Wuyi Moutain,. These activities make a good cultural promotion effect. But these activities need to be held on a regular basis, and effective bundled or extensive publicity, only in this way can finally form the band effect and attract more tourists ${ }^{[8]}$.

At present festival activities of Old Summer Palace give priority to dozen brands of four seasons activities, which has strong brand characteristics. The content of activities is closed to the theme of the four seasons, but is not well combined with cultural connotation interpretation. The suggestion is to improve festival activities and combining different festival celebrations held in the history of the gardens. In history the royal would organize palace guards to attend grand dragon boat race in Fuhai, the emperor will lead nobles to view races in "yingzhou". Nowadays we can restore the dragon boat race according to historical data, create a cultural atmosphere of the Old Summer Palace from the aspects of site, competition system, clothing, prizes and etc, in order to enhance overall perception of tourists.

\section{Conclusion}

Relic activation is an important way to fully convey the site value, give full play to its social cultural function. The key of the site activation is to emphasize essence of culture, on the premise of insisting on protection and authenticity, vividly show cultural information involved in ruins. The activation of the Summer Palace could be done from the aspect of body activation and activity activation. Form the view of body site, combination of the display mode can be adopted; from the view of activity activation, we can improve tourist site cognitive participation experience through ways of scene reappearance, multi mode of narration, festival activities or through multi sensory stimulus to show the brilliance of royal garden and fantastic landscape gardening art. 


\section{REFERENCES}

[1] Yu Xuecai, 2010.Heritage activation - the protection and use of the road to a win-win. Architecture and culture,pp. 17-20

[2] Wu Bihu, Yu Xi,2010.Principles of Tourism

Planning.Beijing: China Tourism Press,pp. 401-422.

[3]Lowenthal, 1979b. 'Envrionmental perception: preserving th e past'.Progress in Human Geography, 3(4),pp.59-59.

[4] Yu Xuecai,2009. New concept in heritage protection: Informational protection and economy. Architecture and culture,pp. 08-11.

[5] Darren J.Timothy, Stevens W. Boyd, 2007.mainly translated by Cheng Jinneng.Heritage Tourism,Beijing:Tourism Education Press,pp.199-231

[6] ZhongXingming.,2007. A Study on Tourism Interpretation System and Sustainable Development of World Cultural Heritage Sites. Tourism Study,pp.291-295.

[7]Beck. Larry \& Cable. Ted T, 1998.Interpretation for the 21st Century: Fifteen Guiding Principles for Interpreting Nature and Culture[M].Sagamore Pub, pp.35-37.

[8]Yu Fangfang,LiuFang,2008. The theory of The Three Kingdoms culture tourism resources and its value . olkway, pp.168-169. 